\title{
Principles of the Patient-Centered Medical Home and Preventive Services Delivery
}

Jeanne M. Ferrante, $M D, M P H^{1,2,3}$

Bijal A. Balasubramanian, MBBS, $\mathrm{PbD}^{1,3}$

Shawna $V$. Hudson, $P b D^{1,3}$

Benjamin F. Crabtree, $\mathrm{PbD}^{1,3,4}$

'Department of Family Medicine, UMDNJ-Robert Wood Johnson Medical School, New Brunswick, New Jersey

${ }^{2}$ Department of Family Medicine, UMDNJ-New Jersey Medical School, Newark, New Jersey

${ }^{3}$ The Cancer Institute of New Jersey, UMDNJ-Robert Wood Johnson Medical School, New Brunswick, New Jersey

${ }^{4}$ Department of Epidemiology, UMDNJ-School of Public Health, Piscataway, New Jersey

\begin{abstract}
PURPOSE Limited research exists examining the principles of the patient-centered medical home (PCMH) and improved outcomes. We examined whether PCMH principles (personal physician, physician-directed team, whole-person orientation, coordination of care, quality and safety, and enhanced access) are associated with receipt of preventive services.
\end{abstract}

METHODS We undertook cross-sectional analyses using baseline patient and practice member surveys and chart audits from a quality improvement trial in 24 primary care offices. Association of PCMH principles with preventive services (receipt of cancer screening, lipid screening, influenza vaccination, and behavioral counseling) was examined using hierarchical linear modeling.

RESULTS Higher global PCMH scores were associated with receipt of preventive services $(\beta=2.3 ; P<.001)$. Positive associations were found with principles of personal physician $(\beta=3.7 ; P<.001)$, in particular, continuity with the same physician $(\beta=4.4 ; P=.002)$ and number of visits within 2 years $(15 \%$ higher for patients with 13 or more visits; $P<.001)$; and whole-person orientation $(\beta=5.6$; $P<.001)$, particularly, having a well-visit within 5 years $(\beta=12.3 ; P<.001)$ and being treated for chronic diseases $(6 \%$ higher if more than 3 chronic diseases; $P=.002$ ). Having referral systems to link patients to community programs for preventive counseling $(\beta=8.0 ; P<.001)$ and use of clinical decision-support tools $(\beta=5.0 ; P=.04)$ were also associated with receipt of preventive services.

CONCLUSIONS Relationship-centered aspects of PCMH are more highly correlated with preventive services delivery in community primary care practices than are information technology capabilities. Demonstration projects and tools that measure $\mathrm{PCMH}$ principles should have greater emphasis on these key primary care attributes.

Ann Fam Med 2010;8:108-116. doi10.1370/afm.1080

\section{INTRODUCTION}

7 he patient-centered medical home (PCMH) is being promoted as the future of primary care practice that will help reform the US health care system into one that is more accessible, effective, efficient, safe, and economical. ${ }^{1}$ The $\mathrm{PCMH}$ includes several principles: (1) an ongoing relationship with a personal physician for first-contact, continuous, and comprehensive care ${ }_{i}(2)$ a physician-directed team that collectively cares for the patient ${ }_{i}(3)$ whole-person orientation, including acute, chronic, preventive, and end-of-life care ${ }_{i}(4)$ coordinated care across all elements of the health care system and the patient's community $_{i}(5)$ quality and safety through evidence-based medicine and clinical decision-support tools, information technology, registries, and continuous quality improvement ${ }_{i}(6)$ enhanced access, achieved through such systems as open scheduling, expanded hours, and new options for communication between patients, their physician, and practice staff; and (7) payment reform to reflect the added value that a PCMH provides to patients. ${ }^{2}$ 
Despite widespread attention and endorsement by both public and private sectors ${ }^{3}$ there has been limited research evaluating principles of the $\mathrm{PCMH}$ or testing the effectiveness of this model in community practices. Most PCMH demonstration and pilot projects require designation by the National Committee for Quality Assurance (NCQA) as a PCMH before participation. ${ }^{4}$ The NCQA's qualification tool, however, may not be best at measuring PCMH principles, as it underemphasizes the high-touch primary care attributes that are relationship centered (first-contact care, longitudinal and continuous care, comprehensive care, and coordination of care $)^{5}$ and overemphasizes the high-tech information technology capabilities. ${ }^{6}$

Several studies have demonstrated the benefits of high-touch primary care attributes in improving health services and outcomes. First-contact care (availability and accessibility of services) is associated with higher rates of breast examinations and Papanicolaou smears, ${ }^{7}$ lower hospitalization rates, ${ }^{8}$ and lower costs of care. ${ }^{9}$ Longitudinal care and continuity of care are associated with higher delivery of preventive services, ${ }^{10-12}$ higher immunization rates, ${ }^{13-16}$ fewer emergency department visits ${ }_{1}^{11,17}$ lower hospitalization rates ${ }^{10,16}$ improved diabetes control ${ }_{1}^{18,19}$ lower health care costs, ${ }_{,}^{16,20}$ and higher patient satisfaction. ${ }^{13,21-24}$ Higher coordination of care is associated with higher rates of preventive screening services, ${ }^{15,25}$ improved diabetes monitoring, ${ }^{25}$ improved depressive symptoms, ${ }^{26}$ greater patient satisfaction, ${ }^{25,27}$ and lower emergency department visits ${ }^{28}$ and hospitalization rates. ${ }^{27}$ Comprehensive primary care is associated with greater rates of physician inquiry and treatment for depression. ${ }^{29}$

The evidence showing effectiveness of high-tech information technology in improving quality of care in outpatient settings has come mostly from studies in 4 large institutions with internally developed electronic medical records (EMRs), academic health centers, or staff-model managed care organizations. ${ }^{30}$ These studies showed that computer-generated, paper-based reminders increased preventive screening and counseling services, discussions of advance directives, and guideline adherence to hypertension treatment. Decision-support systems decreased the overall number of tests ordered and decreased costs, but they had no effect on depression care or laboratory monitoring after initiation of new medications. ${ }^{30,31}$ Studies on effectiveness of health information technology in community primary care settings have shown mixed results. Presence of clinical information and decision-support systems were associated with improvements in glycemic control in patients with diabetes in 1 study, but not with outcomes in patients with heart disease or in treatment of depression. ${ }^{32}$ Other studies showed EMR use increased testing in patients with diabetes but did not improve glycemic control, ${ }^{33,34}$ whereas 1 study showed decreased testing and poorer diabetes control in practices with EMRs compared with practices without. ${ }^{35}$ Although use of electronic prescribing systems have been associated with lowered prescription drug costs, ${ }^{36}$ it has not lowered medication errors or adverse drug events. ${ }^{37}$

There has been little consistency in measuring core concepts of primary care or PCMH. ${ }^{10,38}$ Most studies have relied only on patient reports of the primary care experience. Few publications examine PCMH principles in their entirety. This study uses multiple data sources to examine the association of $\mathrm{PCMH}$ principles with receipt of preventive services in community primary care practices. Because the practices in this study were not part of a PCMH demonstration project with new payments provided to practices, payment reform, although a critical principle of the PCMH, was not included.

\section{METHODS}

\section{Sources of Data}

This study is a secondary analysis of cross-sectional data collected between January 2006 and May 2007 in 24 primary care practices of the New Jersey Family Medicine Research Network. Practices were participating in a randomized controlled intervention study, SCOPE (Supporting Colorectal Cancer Outcomes through Participatory Enhancements), to evaluate the effectiveness of a quality improvement strategy in improving colorectal cancer screening, however, data collection addressed issues beyond colorectal cancer screening. We analyzed baseline data from surveys of patients, practice members, and medical directors and from chart audits. The Institutional Review Board of University of Medicine and Dentistry of New Jersey (UMDNJ)-Robert Wood Johnson Medical School approved this study.

\section{Patient Surveys}

Patient surveys came from 30 patients, aged 50 years or older, recruited consecutively from the waiting areas in each practice. Aged 50 years or older was used as an inclusion criterion to meet colorectal cancer-screening recommendations. ${ }^{39}$ Patients on their first visit and those who were not literate in English or Spanish were excluded. All patients completed a questionnaire that collected demographics, cancer risk factors, health behaviors, self-rated health, and satisfaction with care. Patients also reported on some PCMH elements, such as first contact, continuity, and access to care, as well as receipt of health behavior counseling. Questions related to PCMH elements came from previously published 
scales (Flocke's Components of Primary Care Instrument and Safran's Primary Care Assessment Survey). ${ }^{40,41}$

\section{Chart Audits}

All patients consented to have their charts reviewed. Using a standardized abstraction form, nurse chart auditors collected information on demographics, visits to the practice, medical conditions, dates of cancer screenings, immunizations, health behavior counseling, and lipid screening.

\section{Practice Member Questionnaires}

All practice members were asked to complete a questionnaire that assessed demographics and perceptions about the organization, including leadership and decision-making approaches, communication among members, stress or chaos in practice, and history of change in the practice. ${ }^{42}$ Questions were also asked about practice management. The average response rate was $90 \%$.

\section{Medical Director Surveys}

Each medical director completed a questionnaire on practice composition (clinical specialties and types of clinicians), practice ownership, office volume, sites of care, use of risk assessment tools, system supports for quality improvement, and health information technology.

\section{Outcome Measures}

The primary outcome was the rate at which patients were up-to-date on preventive services (cancer screening, lipid screening, influenza vaccination, and behavioral counseling). For each patient, we calculated the total number of services received within the recommended time interval, divided by the total number of services for which that patient was eligible. As all patients were age eligible, we determined eligibility based on sex and other risk factors: breast cancer screening (all women), cervical cancer screening (all women without a hysterectomy), colorectal cancer screening (everyone), lipid screening (everyone), influenza vaccination (everyone), health behavioral counseling (diet or weight loss counseling in patients with body mass index greater than 25, exercise counseling in everyone, and smoking cessation counseling in current smokers).

Preventive services were assessed by searching the medical record for any documentation of tests, including progress reports, preventive care flow sheets, laboratory tests, radiographs, and consultant reports. To prevent a Hawthorne effect, preventive services were assessed retrospectively, with the index visit considered the last visit before the date of recruitment. Cancer screening was assessed based on 2007 American Cancer Society rec- ommendations: (1) breast cancer (mammogram within 1 year), (2) cervical cancer (Papanicolaou smear within 3 years), and (3) colorectal cancer (fecal occult blood test [FOBT] within 1 year, sigmoidoscopy or doublecontrast barium enema within 5 years, or colonoscopy within 10 years). ${ }^{39}$ Patients were considered up-to-date if they had documentation of receiving cancer screenings in the recommended time period from the index visit plus a 3-month grace period to allow for sufficient time for a recommended service to be completed. ${ }^{43}$

Patients were considered to have received lipid screening and influenza vaccination if their records documented lipid testing within 5 years ${ }^{44}$ and influenza vaccination within 1 year. ${ }^{45}$ Because health behavior counseling is poorly documented ${ }_{r}^{46}$ we used patient survey data to assess receipt of counseling. Patients who answered yes to counseling received in the office within the past year for diet/weight loss, exercise, or smoking were considered to have received health behavior counseling. ${ }^{47}$

\section{Independent Variables}

The main independent variables of interest were principles of the PCMH. ${ }^{2}$ Table 1 displays the data sources used to measure each principle. The research team, consisting of 2 family physicians, an epidemiologist, sociologist, and medical anthropologist, selected items from data collected in SCOPE that best represented indicators of $\mathrm{PCMH}$ principles based on its definition. These measures were presented to 14 physician members of the department for validation and refinement. We first tested each indicator within each principle separately in hierarchical linear models. Subsequently, a summary score was calculated for each principle. Because indicators came from different data sources with different response ranges, to create the summary score, responses from each indicator within each principle were dichotomized and summed. Numerical items were dichotomized based on the median response, such as months enrolled in practice (60 or fewer months $=1$ vs more than 60 months $=0)$ and number of visits in previous 2 years $(8$ or fewer $=1$ vs more than $8=0$ ). Items that contained Likert scale responses were dichotomized as 1 (agree, strongly agree) vs 0 (neutral, disagree, strongly disagree). Likewise, a score of 1 was given for (always/usually) and 0 for (sometimes/rarely/never).

A high-touch score (range, 0-14) was created by adding the summary scores for the relationship-centered principles (personal physician, physician-directed team, whole-person orientation, coordinated care). A high-tech score (range, 0-7) was created by adding the summary scores for quality and safety and enhanced access principles. Because there is no current agreement 
Table 1. Data Sources and Indicators Used to Measure the Principles of the Patient-Centered Medical Home

\begin{tabular}{|c|c|c|}
\hline Principle & Data Source & Indicator \\
\hline \multirow[t]{4}{*}{$\begin{array}{l}\text { Personal physician: ongoing relationship for first- } \\
\text { contact, continuous, and comprehensive care }\end{array}$} & \multirow[t]{2}{*}{ Patient survey } & $\begin{array}{l}\text { "When I get sick, I contact this practice first (before going to a } \\
\text { specialist or emergency room)." }\end{array}$ \\
\hline & & $\begin{array}{l}\text { "How often do you see the same doctor when getting care at this } \\
\text { practice?"a }\end{array}$ \\
\hline & \multirow[t]{2}{*}{ Chart audit } & Number of months seen at practice \\
\hline & & Number of visits in past 2 years \\
\hline \multirow{3}{*}{$\begin{array}{l}\text { Physician-directed team: physician leads team of } \\
\text { individuals who care for patients }\end{array}$} & \multirow[t]{2}{*}{ Director survey } & Practice has nurse practitioners or physician assistants ${ }^{b}$ \\
\hline & & Use of nurses or health educators for preventive counseling ${ }^{b}$ \\
\hline & $\begin{array}{l}\text { Practice member } \\
\text { survey }\end{array}$ & "This practice encourages nursing staff input for making changes." \\
\hline \multirow{3}{*}{$\begin{array}{l}\text { Whole-person orientation: Care for all stages of } \\
\text { life, acute care, chronic care, preventive ser- } \\
\text { vices, end of life care }\end{array}$} & \multirow[t]{3}{*}{ Chart audit } & Patient has well-visit in last 5 years ${ }^{b}$ \\
\hline & & Patient was treated at practice for acute illness ${ }^{b}$ \\
\hline & & Number of chronic diseases \\
\hline \multirow{4}{*}{$\begin{array}{l}\text { Care coordination: coordinated/integrated across } \\
\text { all elements of complex health system-within } \\
\text { practice and between consultants, ancillary pro- } \\
\text { viders, and community resources }\end{array}$} & \multirow[t]{2}{*}{$\begin{array}{l}\text { Practice member } \\
\text { survey }\end{array}$} & $\begin{array}{l}\text { "We have a system to make sure results from testing/consultation } \\
\text { reports are available during patient visits."c }\end{array}$ \\
\hline & & $\begin{array}{l}\text { "We have a system for communicating results from testing to } \\
\text { patients." }\end{array}$ \\
\hline & \multirow[t]{2}{*}{ Director survey } & $\begin{array}{l}\text { Use of referral system to link patients with community programs } \\
\text { for education, support, or preventive counseling }\end{array}$ \\
\hline & & Clinicians make hospital or nursing home visits ${ }^{b}$ \\
\hline \multirow{4}{*}{$\begin{array}{l}\text { Quality and safety: achieved through physician- } \\
\text { patient partnerships, evidence-based medicine, } \\
\text { clinical decision-support tools, continuous } \\
\text { quality improvement, patient participation and } \\
\text { feedback, information technology, voluntary } \\
\text { recognition process }\end{array}$} & \multirow[t]{4}{*}{ Director survey } & Use of electronic medical records ${ }^{b}$ \\
\hline & & $\begin{array}{l}\text { Use of information technology (PDA, online literature searching, } \\
\text { CD or Internet-based knowledge bases) }\end{array}$ \\
\hline & & $\begin{array}{l}\text { Use of clinical decision-support tools (reminder systems for identifying } \\
\text { patients due for screening, prompting clinicians about needed tests, } \\
\text { reminding patients about visits, checklists/flowcharts for chronic dis- } \\
\text { ease or screening, risk factor chart stickers or electronic flags) }\end{array}$ \\
\hline & & $\begin{array}{l}\text { Continuous quality improvement (use of patient satisfaction surveys, } \\
\text { periodic chart audits) }\end{array}$ \\
\hline \multirow{4}{*}{$\begin{array}{l}\text { Enhanced access: through systems such as open } \\
\text { scheduling, expanded hours, new options for } \\
\text { communication }\end{array}$} & \multirow[t]{2}{*}{ Patient survey } & "How long you waited to get an appointment"d \\
\hline & & "Getting through to the office by phone"d \\
\hline & \multirow[t]{2}{*}{ Director survey } & Use of e-mail with patients ${ }^{b}$ \\
\hline & & Use of Web site for marketing ${ }^{b}$ \\
\hline \multicolumn{3}{|l|}{$C D=$ computer disk $;$ PDA = personal digital assistant. } \\
\hline \multicolumn{3}{|l|}{ a $0=$ never, $1=$ rarely, $2=$ sometimes, $3=$ usually, $4=$ always } \\
\hline \multicolumn{3}{|c|}{ ' 1 = strongly disagree, 2 = disagree, $3=$ neutral, $4=$ agree, $5=$ strongly agree } \\
\hline
\end{tabular}

on which of the PCMH principles are more important, we counted all variables equally. Finally, a global PCMH score (range, 0-21) was calculated by adding the summary scores for each PCMH principle. Potential confounding variables, ascertained from patient surveys, included age, sex, race/ethnicity, education level, health insurance status, and self-reported health.

\section{Statistical Analysis}

Descriptive statistics summarize patient and practicelevel characteristics and rates of preventive services. Patient-level characteristics and rate of preventive services delivery were calculated first as an average of all patients within each practice and then averaged across all practices in the study. $t$-Test or analysis of variance was used to assess the relationship between patient characteristics and the mean percentage of eligible preventive services that were received. Hierarchical linear modeling, using the GENMOD procedure in SAS, was performed to account for correlation between patients within practices. Models applied generalized estimating equations with a working correlation matrix and an exchangeable structure using the GENMOD procedure within the SAS/STAT software (SAS system for Windows, version 9.1.3; SAS Institute Inc, Cary, North Carolina). Less than $5 \%$ of data were missing; therefore, missing data were not included in the modeling. The intraclass correlation coefficient, which estimates the effects of clustering of patients within practices, was 0.08 , indicating that $8 \%$ of the variance was explained 
by clustering. Separate regression models were performed testing the association of percentage of preventive services received with (1) each indicator within each principle, (2) each principle using summary scores, (3) the high-touch and high-tech scores, and (4) the global PCMH score. Regression results are presented for individual indicators, as well as dichotomized summary scores, to demonstrate how well they correlate with each other. All models controlled for patient age, sex, race/ethnicity, education level, insurance status, and self-rated health. Adjusted $\beta$ coefficient, 95\% confidence intervals, and $P$ values for each association are reported. All reported $P$ values are 2-tailed, with statistical significance set at an $\alpha$ level of .05.

\section{RESULTS}

There were 742 patients who consented, completed patient questionnaires, and had medical records available for review ( $80 \%$ recruitment rate). For this analysis, we excluded patients enrolled in the practice for fewer than 12 months because they might not have records of preventive services documented, leaving an analytic sample of 568 patients. Table 2 provides patient and practice characteristics of the study sample.

\begin{tabular}{|c|c|}
\hline Characteristic & Value \\
\hline \multicolumn{2}{|l|}{ Patients ( $N=568$ ) } \\
\hline Age, mean (SD), y & $64.4(4.3)$ \\
\hline Sex, male, mean (SD), \% & $39.7(11.8)$ \\
\hline Race, nonwhite, mean (SD), \% & $31.3(31.9)$ \\
\hline Insurance, commercial, mean (SD), \% & $51.6(24.3)$ \\
\hline Education level, high school or less, mean (SD), \% & $36.2(17.9)$ \\
\hline \multicolumn{2}{|l|}{ Practices $(\mathrm{N}=24)$} \\
\hline \multicolumn{2}{|l|}{ Type of practice, $n(\%)$} \\
\hline Family medicine & $17(70.8)$ \\
\hline Internal medicine & $5(20.8)$ \\
\hline Family and internal medicine & $2(8.3)$ \\
\hline \multicolumn{2}{|l|}{ Years in business, $\mathrm{n}(\%)$} \\
\hline $0-5$ & $7(29.2)$ \\
\hline $6-10$ & $6(25.0)$ \\
\hline $11-15$ & $4(16.7)$ \\
\hline $16-20$ & $4(16.7)$ \\
\hline$>20$ & $3(12.5)$ \\
\hline \multicolumn{2}{|l|}{ Clinicians per practice, $\mathrm{n}(\%)$} \\
\hline 1 & $3(12.5)$ \\
\hline $2-5$ & $14(58.3)$ \\
\hline$\geq 6$ & $7(29.2)$ \\
\hline \multicolumn{2}{|l|}{ Practice ownership, n (\%) } \\
\hline Physician owned & $17(73.9)$ \\
\hline Hospital or university & $5(21.7)$ \\
\hline Public sponsor & $1(4.4)$ \\
\hline
\end{tabular}

The mean age of patients was 64 years (SD, 4.3 years). A higher proportion of patients were white, female, commercially insured, and college educated. Thirtyseven percent of practices had midlevel clinicians, and $46 \%$ used electronic medical records. Practice-level mean rates of preventive services delivery were mammography (41\%; SD, 25\%), Papanicolaou smears (47\%; SD, 27\%), colorectal cancer (53\%; SD, 16\%), lipid screening $(77 \%$; SD, $8 \%)$, influenza vaccination $(23 \%$; SD, $15 \%)$, diet or weight loss counseling $(66 \%$; SD, $12 \%)$, exercise counseling $(58 \%$; SD, $12 \%)$, and smoking cessation counseling $(80 \% ; \mathrm{SD}, 27 \%)$.

Table 3 describes the association of patient characteristics (potential confounders) with rates of preventive services delivery. On average, the rate at which patients were up-to-date on preventive services was $42.7 \%$ (SD, 20.4\%). Higher receipt of preventive services was significantly associated with male sex, with being black or Hispanic, and with insurance other than Medicare or commercial.

Table 4 shows the association between preventive service delivery and each indicator of PCMH prin-

Table 3. Association of Patient Characteristics With Percentage of Preventive Services Received $(\mathrm{N}=568)$

\begin{tabular}{|c|c|c|}
\hline Patient Characteristic ${ }^{a}$ & Mean (SD) ${ }^{\mathrm{b}}$ & $\begin{array}{c}P \\
\text { Value }\end{array}$ \\
\hline Rate of preventive services delivery & $42.7(20.4)$ & \\
\hline Age, y & & .26 \\
\hline $50-59$ & $43.1(20.7)$ & \\
\hline $60-69$ & $44.4(20.9)$ & \\
\hline$\geq 70$ & $40.8(19.6)$ & \\
\hline Sex & & .01 \\
\hline Male & $45.3(20.6)$ & \\
\hline Female & $41.0(20.1)$ & \\
\hline Race & & .03 \\
\hline White & $41.3(20.3)$ & \\
\hline Black & $45.2(21.1)$ & \\
\hline Hispanic & $49.0(19.4)$ & \\
\hline Other & $42.8(18.5)$ & \\
\hline Insurance & & .02 \\
\hline Commercial & $40.9(19.4)$ & \\
\hline Medicare & $42.8(21.0)$ & \\
\hline Other & $50.1(20.2)$ & \\
\hline Education level & & .55 \\
\hline Less than high school & $44.1(19.8)$ & \\
\hline High school diploma or some college & $41.2(19.6)$ & \\
\hline College or graduate school degree & $43.0(20.9)$ & \\
\hline Self-rated health & & .06 \\
\hline Excellent/good & $41.5(20.5)$ & \\
\hline Fair/poor & $44.8(20.3)$ & \\
\hline \multicolumn{3}{|c|}{$\begin{array}{l}\text { a Confounding variables used in multivariate models. } \\
\text { b Mean percentage of preventive services that was up-to-date (total number } \\
\text { of services for which patients received divided by the total number of services } \\
\text { patients were eligible) and standard deviation across practices. }\end{array}$} \\
\hline
\end{tabular}


ciples, as well as summary scores. On average, practices scored 11.53 (SD, 2.38) on the global PCMH score, 7.25 (SD, 1.83) on the high-touch score, and 4.28 (SD, 1.43) on the high-tech score. A higher global PCMH score was associated with higher receipt of preventive services. Each 1-point increase in the global PCMH score was associated with $2.3 \%$ increase in the mean percentage of preventive services that were up-todate. This relationship resulted from positive associations with 2 of the 4 high-touch principles (personal physician and whole-person orientation). There was a dose-response effect of number of patient visits on our outcome. Compared with having fewer than 5 visits in the past 2 years, having 13 or more visits was associated
Table 4. Association of Principles of PCMH With Percentage of Preventive Services Received

\begin{tabular}{|c|c|c|}
\hline \multirow[b]{2}{*}{ Principles of PCMH } & \multicolumn{2}{|c|}{$\begin{array}{l}\text { Receipt of } \\
\text { Preventive Services }\end{array}$} \\
\hline & $\beta^{a}(95 \% \mathrm{Cl})$ & $P$ Value \\
\hline Global PCMH score & $2.3(1.4$ to 3.2$)$ & $<.001$ \\
\hline High-touch principles & $3.4(2.2$ to 4.5$)$ & $<.001$ \\
\hline Personal physician & 3.7 (1.7 to 5.8$)$ & $<.001$ \\
\hline Months patient enrolled in practice & $0.03(-0.01 \text { to } 0.07)^{b}$ & $.13^{\mathrm{b}}$ \\
\hline Number of visits in previous 2 years & $0.9(0.6 \text { to } 1.3)^{b}$ & $<.001^{\mathrm{b}}$ \\
\hline$<5$ & Ref & \\
\hline $5-8$ & 9.6 (4.6 to 14.7$)$ & $<.001$ \\
\hline $9-12$ & 12.4 (7.6 to 17.2$)$ & $<.001$ \\
\hline$\geq 13$ & 15.3 (10.6 to 20.1) & $<.001$ \\
\hline Patient sees same doctor when getting care at practice & $4.4(1.6$ to 7.1$)$ & .002 \\
\hline Patient contacts primary care practice first when ill & $0.5(-1.3$ to 2.3$)$ & .56 \\
\hline Physician-directed team & $1.8(-1.8$ to 5.4$)$ & .32 \\
\hline Practice has nurse practitioners or physician assistants & $0.5(-5.4$ to 6.5$)$ & .86 \\
\hline $\begin{array}{l}\text { Practice uses nurses/health educators for preventive } \\
\text { counseling }\end{array}$ & $3.1(-2.6$ to 8.7$)$ & .29 \\
\hline $\begin{array}{l}\text { Practice leadership seeks nursing input for making } \\
\text { changes }\end{array}$ & $1.0(-1.2$ to 3.4$)$ & .37 \\
\hline Whole-person orientation & $5.6(4.2$ to 7.1$)$ & $<.001$ \\
\hline Well-visit in last 5 years & $12.3(7.6$ to 17.1$)$ & $<.001$ \\
\hline Treated at practice for acute illness & 0.7 (-3.9 to 5.3$)$ & .78 \\
\hline Number of chronic diseases & $2.8(1.8 \text { to } 3.8)^{b}$ & $<.001^{\mathrm{b}}$ \\
\hline$\leq 3$ & Ref & \\
\hline$\geq 4$ & $5.8(2.8$ to 8.8$)$ & $<.001$ \\
\hline Coordination of care & $1.4(-0.7$ to 3.5$)$ & .20 \\
\hline $\begin{array}{l}\text { Reports from tests/consultations available during patient } \\
\text { visits }\end{array}$ & $0.4(-4.2$ to 4.9$)$ & .87 \\
\hline Results of tests communicated to patients & $2.5(-0.5$ to 5.6$)$ & .10 \\
\hline Referral system to link patients to community programs & $8.0(3.8$ to 12.3$)$ & $<.001$ \\
\hline Clinicians make hospital or nursing home visits & $0.9(-4.4$ to 6.2$)$ & .74 \\
\hline High-tech principles & $0.3(-1.1$ to 1.7$)$ & .64 \\
\hline Quality and safety & $0.8(-1.2$ to 2.8$)$ & .45 \\
\hline Use of electronic medical records & $-2.1(-7.8$ to 3.7$)$ & .48 \\
\hline Use of information technology & $1.1(-4.3$ to 6.6$)$ & .68 \\
\hline Use of clinical decision support tools & $5.0(0.3$ to 9.7$)$ & .04 \\
\hline Performs continuous quality improvement & $1.6(-3.4$ to 6.6$)$ & .52 \\
\hline Enhanced access & $-0.3(-2.3$ to 1.7$)$ & .74 \\
\hline Waiting time for appointment & $-0.2(-1.4$ to 1.0$)$ & .76 \\
\hline Getting through the office by telephone & $-0.4(-1.9$ to 0.9$)$ & .52 \\
\hline Use of Web site for marketing & $-0.3(-5.8$ to 5.2$)$ & .91 \\
\hline \multicolumn{3}{|l|}{ PCMH = patient-centered medical home; Ref = reference . } \\
\hline \multicolumn{3}{|c|}{$\begin{array}{l}\text { adjusted for patient age, sex, race/ethnicity, education level, insurance status, and self-rated health while } \\
\text { accounting for correlation between patients within practices. Each } \beta \text { is from a separate model. } \\
{ }^{b} \text { Analyzed as continuous variable. } \\
\text { ' Use of e-mail with patients was not included in multivariate models because of unstable estimates (only } \\
3 \text { practices used e-mail). }\end{array}$} \\
\hline
\end{tabular}

with $15.3 \%$ increase in the mean percentage of preventive services received. In addition, seeing the same doctor, having a well-visit in the last 5 years, and having a referral system to link patients to community programs were significantly associated with higher rates of preventive services. The only high-tech indicator that was significantly associated with receipt of preventive services was use of clinical decision-support tools.

\section{DISCUSSION}

Current evidence about benefits of medical homes comes predominantly from the pediatric literature regarding children with special health care needs. A review of this literature, using an earlier definition of medical home that focused on relationship-centered attributes of primary care, found that these attributes were generally positively associated with better health outcomes, but findings were mixed and definitions and outcomes measured were inconsistent. ${ }^{38} \mathrm{No}$ study examined all of the medical home attributes together. To our knowledge, this report is the first examining the association of PCMH principles in their entirety with a broad range of preventive services in adults. We found that a higher global PCMH score was associated with higher receipt of preventive services, mainly resulting from positive associations with the high-touch relationship-centered principles (personal physician and whole-person orientation), which are core to primary care. 
Our findings are consistent with previous studies showing benefits of primary care attributes (longitudinal, continuous care, and coordination of care) on preventive services delivery in community practices. ${ }^{10-16,25}$ Having a greater number of visits and a well-visit in the past 5 years had the greatest effect on preventive services delivery rates. This finding suggests that having more contacts with the primary care practice and having a visit dedicated to preventive care are important strategies to increase preventive services. In addition, having a referral system to link patients to community programs may be an important element of care coordination for improving preventive services delivery. ${ }^{26}$ Enhanced access was not associated with our outcome, contrary to other studies showing availability of primary care increased preventive services rates. ${ }^{7}$ Because all our patients already had access to primary care, it appears that enhancing access further does not improve delivery of preventive services.

Our mean rates of preventive services, particularly for cancer screening (40\% to 54\%) and influenza vaccination $(21 \%)$, were much lower than optimal. Yet, these services are among those most likely to have the largest improvements in population health at most efficient costs. ${ }^{48}$ Limited clinician time and competing demands are among reasons why the current model of primary care is not optimal in delivering preventive services. ${ }^{49}$ Alternative models of delivering primary care therefore need to emphasize evidence-based strategies while not adding to the burdens of primary care physicians, who are often too overwhelmed with day-to-day work to take on new tasks. ${ }^{50}$

There is ample evidence of benefits of primary care on improving health services and outcomes, decreasing health disparities, and reducing health care costs. ${ }^{51}$ In contrast, evidence on benefits of health information technology in improving health in community primary care settings have shown mixed results. ${ }^{32-34,36,37}$ The only indicator of high-tech principles that was marginally associated with preventive services delivery in our sample was use of clinical decision-support tools, which includes reminders, also previously shown to increase preventive services. ${ }^{30}$ Yet, attention and PCMH recognition programs, such as NCQA, give greater emphasis to high-tech principles rather than the high-touch principles that form the core of primary care ${ }^{6}$ Thus, a practice that scores well on the NCQA qualification tool may not necessarily practice patientcentered primary care, whereas practices that are strong in relationship-centered care may get excluded as a medical home by the NCQA qualification tool. Unfortunately, many current PCMH demonstration and pilot programs require certification as a $\mathrm{PCMH}$ by NCQA before participation, and most focus on enhancing information technology capabilities. ${ }^{52}$ By not adequately measuring and emphasizing key $\mathrm{PCMH}$ principles, particularly the core primary care attributes, these projects risk generating null results, which may lead to premature abandonment of the $\mathrm{PCMH}$ concept by major payers.

There are some limitations to be considered in this study. First, our study was a secondary analysis, so we were limited by measures available in the previously collected data set. We acknowledge that the measures used may not be completely congruent with conceptual

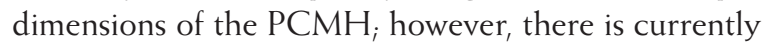
no agreement on how to measure PCMH concepts, because some components are abstract and "difficult to define and quantify. ${ }^{1153}$ Other researchers have measured PCMH principles using physician surveys. ${ }^{54} \mathrm{Few}$ studies have measured PCMH principles from the multiple vantage points of the medical record, patients, and practice members. The current study does so and therefore contributes to the existing literature by suggesting replicable measures of the $\mathrm{PCMH}$ that can be viably assessed within community practice settings.

Second, although a high percentage of our practices used EMRs (46\%, which is much higher than the percentages found in national samples), ${ }^{55}$ we did not have information on functionality of these EMR systems or the length of time practices utilized them. Integrated health information systems take long periods of implementation and adoption, requiring tremendous support that is often not available to independent community primary care practices. ${ }^{56}$ Without this support, benefits of EMRs may not be realized in community primary care practices. ${ }^{57} \mathrm{We}$ evaluated preventive services only, and information technology capabilities may be more important for delivery of chronic disease care. Although most PCMH projects focus on treatment and management of chronic illnesses, improving preventive services delivery may be more cost-effective in achieving improved population health. ${ }^{58}$

Finally, the study design may have introduced some biases. Our analysis was cross-sectional and observational, so causality cannot be conferred from our associations. Our findings, however, are consistent with those of other studies showing benefits of primary care attributes on preventive services delivery. Practices agreeing to participate in SCOPE may have had greater or fewer components of PCMH than those that did not participate. Likewise, patients agreeing to participate might have had higher or lower rates of preventive services than those not agreeing to participate or those excluded (patients who were not literate in English or Spanish.) Using a consecutive series of patients may have introduced some potential biases that were due to patient age, sex, health, employment status, time of 
year of recruitment, or some other unmeasured factors. Patients in this study were mostly white, educated, and insured; therefore, these results might not be generalizable to other patients. These limitations not withstanding, because of the practice sampling strategy, the results should be applicable to other small community primary care practices, which constitute $95 \%$ of outpatient ambulatory care practices. ${ }^{59}$

In conclusion, $\mathrm{PCMH}$ principles are associated with higher rates of preventive services delivery in community primary care practices, with the high-touch relationship-centered principles more highly correlated than information technology capabilities. These findings suggest that $\mathrm{PCMH}$ demonstration projects and tools that measure PCMH principles should have greater emphasis on these key primary care attributes that have strong evidence in improving health care and health outcomes.

To read or post commentaries in response to this article, see it online at http://www.annfammed.org/cgi/content/full/8/2/108.

Key words: Medical home; preventive services; primary health care; health services; health promotion; mass screening; health care delivery; health services research

Submitted May 1, 2009; submitted, revised, September 4, 2009; accepted October 23, 2009.

Portions of this manuscript have been presented at the 36th North American Primary Care Research Group Annual meeting, Puerto Rico, November 15-19, 2008.

Funding support: This research was supported through grants from the National Cancer Institute: R01NCI CA11287 (B.F.C.) and K07CA101780 (J.M.F.). Data collection for this study was funded by a National Cancer Institute grant R01 CA112387 (B.F.C.). This study was also supported by a research career development award (J.M.F.) from the National Cancer Institute (K07CA101780).

Disclaimer: The content is solely the responsibility of the authors and does not necessarily represent the official views of the National Cancer Institute and the National Institutes of Health.

Acknowledgments: This research was conducted in conjunction with the New Jersey Family Medicine Research Network (NJFMRN), a shared resource of the Cancer Institute of New Jersey.

\section{References}

1. Backer LA. The medical home: an idea whose time has come... again. Fam Pract Manag. 2007;14(8):38-41.

2. American Academy of Family Physicians, American Academy of Pediatrics, American College of Physicians, American Osteopathic Association. Joint principles of the patient-centered medical home. 2007. http://www.medicalhomeinfo.org/Joint\%20Statement.pdf. Accessed Nov 19, 2007.

3. Patient-Centered Primary Care Collaborative. Collaborative members. 2009. http://www.pcpcc.net/content/collaborative-members. Accessed Jan 29, 2009.
4. National Committee for Quality Assurance. Physician practice connections-patient-centered medical home. 2009. http://www.ncqa. org/tabid/631/Default.aspx. Accessed Jan 23, 2009.

5. Starfield B. Primary Care: Concept, Evaluation, and Policy. New York, NY: Oxford University Press; 1992.

6. O'Malley AS, Peikes D, Ginsburg PB. Qualifying a physician practice as a medical home. Policy Perspective No. 1. Vol 1. Washington, DC: Center for Studying Health System Change; 2008.

7. Bindman AB, Grumbach K, Osmond D, Vranizan K, Stewart AL. Primary care and receipt of preventive services. J Gen Intern Med. 1996;11(5):269-276.

8. Bindman AB, Grumbach K, Osmond D, et al. Preventable hospitalizations and access to health care. JAMA. 1995;274(4):305-311.

9. Forrest CB, Starfield B. The effect of first-contact care with primary care clinicians on ambulatory health care expenditures. J Fam Pract. 1996;43(1):40-48.

10. Saultz JW, Lochner J. Interpersonal continuity of care and care outcomes: a critical review. Ann Fam Med. 2005;3(2):159-166.

11. Menec VH, Sirski M, Attawar D. Does continuity of care matter in a universally insured population? Health Serv Res. 2005;40(2):389-400.

12. Blewett LA, Johnson PJ, Lee $B$, Scal PB. When a usual source of care and usual provider matter: adult prevention and screening services. J Gen Intern Med. 2008;23(9):1354-1360.

13. O'Malley AS. Current evidence on the impact of continuity of care. Curr Opin Pediatr. 2004;16(6):693-699.

14. Gill JM, Saldarriaga A, Mainous AG III, Unger D. Does continuity between prenatal and well-child care improve childhood immunizations? Fam Med. 2002;34(4):274-280.

15. Flocke SA, Stange KC, Zyzanski SJ. The association of attributes of primary care with the delivery of clinical preventive services. Med Care. 1998;36(8)(Suppl):AS21-AS30.

16. Weiss LJ, Blustein J. Faithful patients: the effect of long-term physician-patient relationships on the costs and use of health care by older Americans. Am J Public Health. 1996;86(12):1742-1747.

17. Gill JM, Mainous AG III, Nsereko M. The effect of continuity of care on emergency department use. Arch Fam Med. 2000;9(4):333-338.

18. Mainous AG III, Koopman RJ, Gill JM, Baker R, Pearson WS. Relationship between continuity of care and diabetes control: evidence from the Third National Health and Nutrition Examination Survey. Am J Public Health. 2004;94(1):66-70.

19. Sperl-Hillen JM, Solberg LI, Hroscikoski MC, Crain AL, Engebretson $\mathrm{KI}, \mathrm{O}^{\prime}$ Connor PJ. The effect of advanced access implementation on quality of diabetes care. Prev Chronic Dis. 2008;5(1):A16.

20. De Maeseneer JM, De Prins L, Gosset C, Heyerick J. Provider continuity in family medicine: does it make a difference for total health care costs? Ann Fam Med. 2003;1(3):144-148.

21. Saultz JW, Albedaiwi W. Interpersonal continuity of care and patient satisfaction: a critical review. Ann Fam Med. 2004;2(5):445-451.

22. Christakis DA, Wright JA, Zimmerman FJ, Bassett AL, Connell FA. Continuity of care is associated with high-quality care by parental report. Pediatrics. 2002;109(4):e54.

23. Sans-Corrales M, Pujol-Ribera E, Gené-Badia J, Pasarín-Rua MI, Iglesias-Pérez B, Casajuana-Brunet J. Family medicine attributes related to satisfaction, health and costs. Fam Pract. 2006;23(3):308-316.

24. Powell Davies G, Williams AM, Larsen K, Perkins D, Roland M, Harris MF. Coordinating primary health care: an analysis of the outcomes of a systematic review. Med J Aust. 2008;188(8)(Suppl):S65-S68.

25. Parkerton PH, Smith DG, Straley HL. Primary care practice coordination versus physician continuity. Fam Med. 2004;36(1):15-21.

26. Stille CJ, Jerant A, Bell D, Meltzer D, Elmore JG. Coordinating care across diseases, settings, and clinicians: a key role for the generalist in practice. Ann Intern Med. 2005;142(8):700-708. 
27. Palfrey JS, Sofis LA, Davidson EJ, Liu J, Freeman L, Ganz ML; Pediatric Alliance for Coordinated Care. The Pediatric Alliance for Coordinated Care: evaluation of a medical home model. Pediatrics. 2004;113(5)(Suppl):1507-1516.

28. Antonelli RC, Stille CJ, Antonelli DM. Care coordination for children and youth with special health care needs: a descriptive, multisite study of activities, personnel costs, and outcomes. Pediatrics. 2008;122(1):e209-e216.

29. O'Malley AS, Forrest CB, Miranda J. Primary care attributes and care for depression among low-income African American women. Am J Public Health. 2003;93(8):1328-1334.

30. Chaudhry B, Wang J, Wu S, et al. Systematic review: impact of health information technology on quality, efficiency, and costs of medical care. Ann Intern Med. 2006;144(10):742-752.

31. Palen TE, Raebel M, Lyons E, Magid DM. Evaluation of laboratory monitoring alerts within a computerized physician order entry system for medication orders. Am J Manag Care. 2006;12(7):389-395.

32. Solberg LI, Crain AL, Sperl-Hillen JM, Hroscikoski MC, Engebretson $\mathrm{KI}, \mathrm{O}^{\prime}$ Connor PJ. Care quality and implementation of the chronic care model: a quantitative study. Ann Fam Med. 2006;4(4):310-316

33. Montori VM, Dinneen SF, Gorman CA, et al; Translation Project Investigator Group. The impact of planned care and a diabetes electronic management system on community-based diabetes care: the Mayo Health System Diabetes Translation Project. Diabetes Care. 2002;25(11):1952-1957.

34. O'Connor PJ, Crain AL, Rush WA, Sperl-Hillen JM, Gutenkauf JJ, Duncan JE. Impact of an electronic medical record on diabetes quality of care. Ann Fam Med. 2005;3(4):300-306.

35. Crosson JC, Ohman-Strickland PA, Hahn KA, et al. Electronic medical records and diabetes quality of care: results from a sample of family medicine practices. Ann Fam Med. 2007;5(3):209-215.

36. McMullin ST, Lonergan TP, Rynearson CS. Twelve-month drug cost savings related to use of an electronic prescribing system with integrated decision support in primary care. J Manag Care Pharm. 2005;11(4):322-332.

37. Gandhi TK, Weingart SN, Seger AC, et al. Outpatient prescribing errors and the impact of computerized prescribing. J Gen Intern Med. 2005;20(9):837-841.

38. Homer CJ, Klatka K, Romm D, et al. A review of the evidence for the medical home for children with special health care needs. Pediatrics. 2008;122(4):e922-e937.

39. Smith RA, Cokkinides V, Eyre HJ. Cancer screening in the United States, 2007: a review of current guidelines, practices, and prospects. CA Cancer J Clin. 2007;57(2):90-104.

40. Flocke SA. Measuring attributes of primary care: development of a new instrument. J Fam Pract. 1997;45(1):64-74.

41. Safran DG, Kosinski M, Tarlov AR, et al. The Primary Care Assessment Survey: tests of data quality and measurement performance. Med Care. 1998;36(5):728-739.

42. Ohman-Strickland PA, John Orzano A, Nutting PA, et al. Measuring organizational attributes of primary care practices: development of a new instrument. Health Serv Res. 2007;42(3 Pt 1):1257-1273.

43. Roetzheim RG, Christman LK, Jacobsen PB, et al. A randomized controlled trial to increase cancer screening among attendees of community health centers. Ann Fam Med. 2004;2(4):294-300
44. Expert Panel on Detection, Evaluation, and Treatment of High Blood Cholesterol in Adults. Executive summary of the third report of The National Cholesterol Education Program (NCEP) expert panel on detection, evaluation, and treatment of high blood cholesterol in adults (Adult Treatment Panel III). JAMA. 2001;285(19):2486-2497.

45. Centers for Disease Control and Prevention. Recommended Adult Immunization Schedule-United States, October 2005-September 2006. MMWR. 2005;54(40):Q1-Q4.

46. Ferrante JM, Ohman-Strickland P, Hahn KA, et al. Self-report versus medical records for assessing cancer-preventive services delivery. Cancer Epidemiol Biomarkers Prev. 2008;17(11):2987-2994.

47. Guide to Clinical Preventive Services. 2006: Recommendations of the U.S. Preventive Services Task Force. June 2006. AHRQ Publication No. 06-0588. http://www.ahrq.gov/clinic/pocketgd06/. Accessed February 19, 2009.

48. Maciosek MV, Coffield AB, Edwards NM, Flottemesch TJ, Goodman MJ, Solberg LI. Priorities among effective clinical preventive services: results of a systematic review and analysis. Am J Prev Med. 2006;31(1):52-61.

49. Yarnall KS, Pollak KI, Østbye T, Krause KM, Michener JL. Primary care: is there enough time for prevention? Am J Public Health. 2003;93(4):635-641.

50. McVea K, Crabtree BF, Medder JD, et al. An ounce of prevention? Evaluation of the 'Put Prevention into Practice' program. J Fam Pract. 1996;43(4):361-369.

51. Starfield B, Shi L, Macinko J. Contribution of primary care to health systems and health. Milbank Q. 2005;83(3):457-502.

52. Patient-Centered Primary Care Collaborative. Patient-centered medical home. Building evidence and momentum. A compilation of PCMH pilot and demonstration projects, 2008. Washington, DC: Patient-Centered Primary Care Collaborative. http://www.pcpcc.net.

53. Carrier E, Gourevitch MN, Shah NR, Carrier E, Gourevitch MN, Shah NR. Medical homes: challenges in translating theory into practice. Med Care. 2009;47(7):714-722.

54. Goldberg DG, Kuzel AJ. Elements of the patient-centered medical home in family practices in Virginia. Ann Fam Med. 2009;7(4):301-308.

55. DesRoches CM, Campbell EG, Rao SR, et al. Electronic health records in ambulatory care-a national survey of physicians. N Engl J Med. 2008;359(1):50-60.

56. Paulus RA, Davis K, Steele GD. Continuous innovation in health care: implications of the Geisinger experience. Health Aff (Millwood). 2008;27(5):1235-1245

57. Crosson JC, Stroebel C, Scott JG, Stello B, Crabtree BF. Implementing an electronic medical record in a family medicine practice: communication, decision making, and conflict. Ann Fam Med. 2005;3(4):307-311.

58. Woolf SH. A closer look at the economic argument for disease prevention. JAMA. 2009;301(5):536-538.

59. Hing $E$, Burt CW. Office-based medical practices: methods and estimates from the national ambulatory medical care survey. Adv Data. 2007;(383):1-15. 